\title{
A Proposed Fuzzy Logic based System for Predicting Surface Roughness when Turning Hard Faced Components
}

\author{
Shamita Murmu \\ M. Tech Student \\ Mechanical Engineering \\ BIT Sindri, Dhanbad, INDIA
}

\author{
S.K. Jha \\ Associate Professor \\ Production Engineering \\ BIT Sindri, Dhanbad, INDIA \\ Vijay Kumar \\ Professor \\ IIMT College of Engineering, \\ Greater NOIDA, INDIA
}

\author{
A.P. Burnwal \\ Assistant Professor \\ Mathematics \\ GGSESTC, Bokaro, INDIA
}

\begin{abstract}
Hard-facing or hard-surfacing process is used for enhancing the service life of various machine parts by reshaping the worn out or eroded or corroded areas in them to improve their wear resistant properties. The hard-faced part contains rough, irregular and wavy surface, hence machining process is applied on them to get smooth finish and also to maintain the required dimension. The present paper is proposing a fuzzy logic based system to predict the surface roughness of a shaft like hard-faced component using some existing experimental data. Cutting speed $(V)$, feed rate $\left(f_{r}\right)$ and depth of cut (DOC) are the three cutting parameters which have been considered here to optimize the surface roughness of a component subjected to hard-facing process.
\end{abstract}

\section{Keywords}

Hard-facing Process, Welding Technique, Turning Process, Fuzzy Logic System, Surface Roughness.

\section{INTRODUCTION}

The process of application of build-up of deposits of specialized alloys by means of fusion welding process mainly to improve the service life of a machine parts either by rebuilding or by fabricating in such a way as to produce a metallic/alloy wall section to withstand the problems of wear, erosion, corrosion, fatigue etc. is known as hard-facing or resurfacing process. Such deposition can be applied on the surface or edge during production to improve the wear resistant properties of the component or merely at the point of a part where it is subjected to wear during servicing or functioning. [9]. A hard-faced part acts like a laminate, where the base metal is chosen for strength and economy and the hard-facing material selected for the specific wearing conditions according to the working environment. It extends the lifetime of machinery equipment efficiently by increasing the service life of its parts. The core components which are exposed to heavy wear during performing their job such as ploughshare points, crusher blades etc. require high wear resistance properties. Hard-facing is the efficient surface protection process for such type of core components. Thus, the purpose behind hard-facing is to avoid costly downtimes and to reduce the cost of expensive spare parts by improving the wear resistant properties and extending their life [5]. Many industries such as cement, mining, steel, petro-chemical, nuclear and steam power plants, chemical and fertilizer plants, agriculture machines and pressure vessels, railways, and in aerospace components have been adopted this process [11]. As hard-faced components contain rough, irregular and wavy surface after deposition of integral layer of material, and good surface finish is necessary to prevent premature fatigue failure, to improve corrosion resistance, to reduce friction, wear and noise, and finally to improve product life. Hence, hard-facing depends on two main factors, heat source used for performing the deposition of alloying elements i.e. welding process, and subsequent machining operation i.e. turning process, milling process etc. depending upon the shape of hard-faced component performed on the hard-faced surface, in order to get required surface quality and surface integrity. In order to get good surface quality characteristics, needs to perform the desired machining operation in a controlled manner, i.e. the process should be performed under optimum condition. Traditionally, to find an optimum condition trial and error method were performed or taking help from the experience of operator. But for a skilled operator too it is difficult to set optimum cutting parameters each time. All these are likely to result in choosing inappropriate cutting conditions.

For the reasons as stated above, there is a tendency to use soft computing technique for optimizing the processes, particularly machining processes. Soft computing techniques are of different types and have already been applied on various manufacturing processes. One of them is fuzzy logic technique that has successfully been applied for optimizing various machining processes.

In this paper a shaft like component which is hard-faced by arc welding technique is considered, and since, turning operation is best suited process for surface finishing of cylindrical shape components, thus, turning has been applied on hard-faced shaft to get desired surface finish and fuzzy logic soft computing technique has been used to optimize the process parameters.

\section{HARD-FACING PROCESSES, BASE AND SURFACE MATERIAL USED IN HARD-FACING AND CUTTING TOOL USED IN TURNING $[3,10]$}

Among various welding techniques to select most suitable one is a complex job. But with considering the following factors it will become an easy task such various factors are nature of work to be hard-faced of the component, function of the component, chemical composition of base metal., accessibility and availability of weld equipment, State of repair of worn components, required number of components to be hardfaced, component's geometry, The desired deposition rate, and replacement cost of the part [8]. 
Hard-facing by arc welding is preferred for the deposition of high-melting-point alloys. In this process, an arc is produced in between two electrodes with the help of power supply this arc is the concentrated heat source that could produce temperature up to $4000^{\circ} \mathrm{C}$ [1].

Arc welding techniques preferably used in hard-facing are
a. Shielded Metal Arc Welding (SMAW),
b. Fluxed Cored Arc Welding (FCAW), And
c. Submerged Arc Welding (SAW).

Base material: [3, 10]

Surface material (weight \%):

Table 1. Chemical composition of Grade 1 and Grade 2 Steel by wt. \% $[3,10]$

\begin{tabular}{|c|c|c|c|c|c|c|c|c|c|c|}
\hline $\begin{array}{l}\text { Elem } \\
\text { ent }\end{array}$ & $\mathrm{C}$ & $\mathrm{Cr}$ & $\begin{array}{l}M \\
n\end{array}$ & $\mathrm{Si}$ & $\begin{array}{l}\text { T } \\
\mathrm{i}\end{array}$ & $\begin{array}{l}\mathrm{M} \\
\mathrm{o}\end{array}$ & $S$ & $\mathrm{P}$ & $\begin{array}{l}\mathrm{C} \\
\mathrm{u}\end{array}$ & $\begin{array}{l}\mathrm{F} \\
\mathrm{e}\end{array}$ \\
\hline $\begin{array}{l}\text { Grad } \\
\text { e } 1\end{array}$ & $\begin{array}{l}0.2 \\
7- \\
0.3 \\
5\end{array}$ & $\begin{array}{l}0 . \\
8- \\
1 . \\
1\end{array}$ & $\begin{array}{l}0 . \\
8- \\
1 . \\
0\end{array}$ & $\begin{array}{l}0 . \\
9- \\
1 . \\
2\end{array}$ & - & - & $\begin{array}{l}0 . \\
04\end{array}$ & $\begin{array}{l}0 . \\
04\end{array}$ & - & $\begin{array}{l}\text { oc } \\
\text { t. }\end{array}$ \\
\hline $\begin{array}{l}\text { Grad } \\
\text { e } 2\end{array}$ & $\begin{array}{l}0.3 \\
2- \\
0.4 \\
0\end{array}$ & $\begin{array}{l}7 . \\
2- \\
8 . \\
0\end{array}$ & $\begin{array}{l}0 . \\
2- \\
0 . \\
3\end{array}$ & $\begin{array}{l}1 . \\
6- \\
1 . \\
8\end{array}$ & - & $\begin{array}{l}0 . \\
1- \\
0 . \\
25\end{array}$ & - & - & $\begin{array}{l}0 . \\
5- \\
0 . \\
6\end{array}$ & - \\
\hline
\end{tabular}

Cutting tool: Cemented tungsten carbide T15K6/T5K10 has been used for cutting in turning process $[3,8]$.

\section{SURFACE FINISHING OF HARDFACED COMPONENT}

Rough surfaces contain micro-irregularities, flaws, lay waviness etc. Due to the presence of such micro- irregularities and waviness on the surface there is reduction in the contact area when this surface is made to rub with other surface, the surface make contact only at the crests. This increases the specific pressure and temperature at the contact area and leads to more intensive deformation, crushing, shearing and chipping of the ridges on both the surfaces, resulting in increased wear of surfaces. Hence, surface quality plays important role in functional ability of any component. Rough surface wear more quickly and have higher friction coefficients than smooth surfaces. Roughness is often a good predictor of the performance of a mechanical component, since irregularities in the surface may form nucleation sites for cracks or corrosion. Although roughness is usually undesirable, it is difficult and expensive to control in manufacturing. Decreasing the roughness of a surface will usually increase exponentially its manufacturing costs. The success of a machining operation is judged by the surface finishing of its machined part [12]. In manufacturing field, the surface finish quality is important and influences the functioning of a component. It is one of the crucial performance parameters that have to be controlled within suitable limits for a particular process. Hence final finishing of hard-faced components is needed because of their ability to satisfy stringent requirements of surface roughness and tolerance related, as it is generally necessary to specify a smoother finish in order to maintain a finer tolerance in production. The reliability of mechanical components, especially for high strength applications, is often critically depending upon the quality of the surface produced by machining. Therefore it is necessary to find a suitable optimization method which can find optimum values of cutting parameters for minimizing surface roughness. Turning is one of the widely used manufacturing processes in industry in which a single point cutting tool is fed linearly in a direction parallel to the axis of rotation of work-piece to remove unwanted materials in order to produce a better surface finish. In this paper cutting speed, feed rate and depth of cut have been taken under consideration to control the surface roughness.

\section{DATA MODELING USING THE FUZZY LOGIC SYSTEM}

Modeling by fuzzy logic (FL) opens up a new way to optimize cutting conditions. FL comprises of fuzzifier, membership functions, rule base, fuzzy inference system and defuzzifier. Fuzzifier expresses the input variables in the form of fuzzy membership values based on various membership functions (MFs). Rule base in linguistic form are formulated on the basis of experimental observations, such as if cutting speed is high, feed rate is slow and depth of cut is low, then surface roughness is low,. On the basis of each rule present in rule base, inference can be drawn on output grade and membership value. To arrive at a final decision inferences obtained from various rules are combined. The membership values thus obtained are defuzzified using various techniques to obtain true value [13].

The structure of a FL system consists of following conceptual components as

a) Fuzzy Rule(FR) base, b) Database , and c) Reasoning mechanism

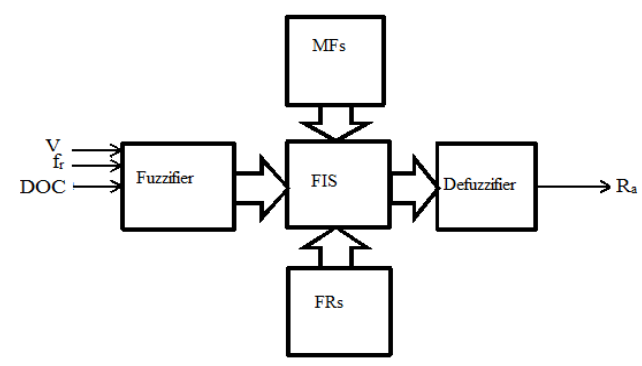

Fig 1: Components of FLS

Linguistic statement which is used to characterize the relationship between input and output is known as FR. Here, FR for $n$ inputs and an output, FL unit is described as follows:

The rule base consists of a group of IF-ELSE statements with four inputs $\mathrm{x}_{1}, \mathrm{x}_{2}, \mathrm{x}_{3}, \mathrm{x}_{4}, \ldots \mathrm{x}_{\mathrm{n}}$ and an output $\mathrm{y}$, i.e.

$\mathrm{FR}_{1}$ : if $\mathrm{x}_{1}$ is $\mathrm{A}_{1}$ and $\mathrm{x}_{2}$ is $\mathrm{B}_{1}$ and $\mathrm{x}_{3}$ is $\mathrm{C}_{1}$ and $\mathrm{x}_{4}$ is $\mathrm{D}_{1}$ .... then $\mathrm{y}$ is $\mathrm{E}_{1}$ else

$F_{2}$ : if $x_{1}$ is $A_{2}$ and $x_{2}$ is $B_{2}$ and $x_{3}$ is $C_{3}$ and $x_{4}$ is $D_{2}$ ..... then $\mathrm{y}$ is $\mathrm{E}_{2}$ else.....

$\mathrm{FR}_{\mathrm{n}}$ : if $\mathrm{x}_{1}$ is $A_{n}$ and $\mathrm{x}_{2}$ is $\mathrm{B}_{\mathrm{n}}$ and $\mathrm{x}_{3}$ is $\mathrm{C}_{\mathrm{n}}$ and $\mathrm{x}_{4}$ is $\mathrm{D}_{\mathrm{n}}$ ..... then $\mathrm{y}$ is $\mathrm{E}_{\mathrm{n}}$ else

Where, $A_{i}, B_{i}, C_{i}, D_{i}$ and $E_{i}$ are fuzzy subsets defined by the corresponding membership functions; that is $\mu_{\mathrm{Ai}}, \mu_{\mathrm{Bi}}, \mu_{\mathrm{Ci}}, \mu_{\mathrm{Di}}$ and $\mu_{\mathrm{Ei}}$.

The process parameters in finish turning process are cutting speed, feed rate, depth of cut, as input parameters and surface 
roughness as output parameters are considered in the present work deals with FL based system which is designed for the prediction of surface finishing for hard-faced components.

\subsection{Design of FLS in MATLAB}

The FLS is applied because of its ability to improve system performance .The membership functions, their numbers, and rule bases are obtained from the FLS. MATLAB software [61] has been used in this work. Steps in designing FLS:

a) Input and output parameters are defined. Shown in figure (5.2)

b) Triangular Membership functions defined for cutting speed, feed rate, depth of cut and surface roughness in figure (5.3), (5.4), (5.5) \& (5.6).

c) Rule base are created on the basis of results of $[4,7]$ using AND operator. Here all three inputs are logically interrelated with each other and according to their combinational effect on process response; the rule base has been generated. As there are three process parameters so overall, 27 rules are involved. The set of 27 FRs involving all linguistic values low (L), medium (M), high $(\mathrm{H})$ is shown in table (5.3)

d) With the Fuzzy inference engine each rule present in rule base are defuzzified using centroid method shown in figure (5.7a).

Table 2. Input process parameters in finish turning process with their levels $[3,10]$

\begin{tabular}{|c|c|c|c|c|c|}
\hline $\begin{array}{c}\text { Input } \\
\text { Parameter }\end{array}$ & $\begin{array}{c}\text { Notation } \\
\mathrm{s}\end{array}$ & $\mathrm{s}$ & Units & \multicolumn{3}{|c|}{ Levels } \\
\cline { 3 - 6 } & & & Low & $\begin{array}{c}\text { Mediu } \\
\mathrm{m}\end{array}$ & High \\
& & & & & \\
& & & $\mathrm{L})$ & $(\mathrm{H})$ & \\
\hline $\begin{array}{c}\text { Cutting } \\
\text { speed }\end{array}$ & $\mathrm{V}$ & $\mathrm{m} / \mathrm{min}$ & $60-$ & $75-105$ & 105 \\
& & & 75 & & - \\
& & & & & 120 \\
\hline Feed rate & $\mathrm{f}_{\mathrm{r}}$ & $\mathrm{mm} / \mathrm{rev}$ & 0.10 & $0.105-$ & 0.11 \\
& & $\cdot$ & - & 0.115 & $5-$ \\
& & & 0.10 & & 0.12 \\
& & & 5 & & 0 \\
\hline $\begin{array}{c}\text { Depth of } \\
\text { cut }\end{array}$ & DOC & $\mathrm{Mm}$ & 0.20 & $0.205-$ & 0.21 \\
& & & - & 0.215 & $5-$ \\
& & & 0.20 & & 0.22 \\
& & & 5 & & 0 \\
\hline
\end{tabular}

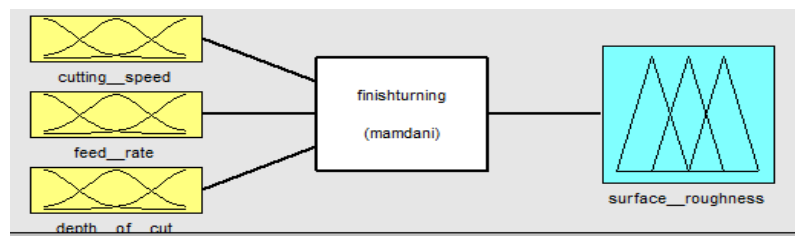

Figure 2: FLS in MATLAB

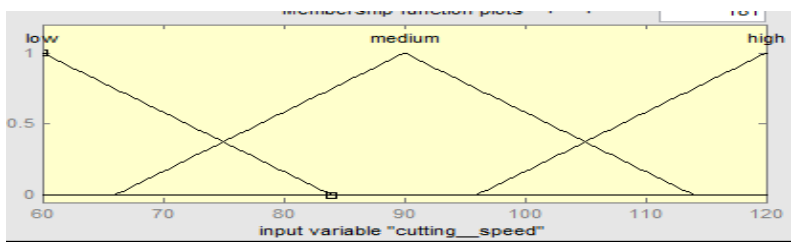

Fig. 3: Membership function vs. cutting speed

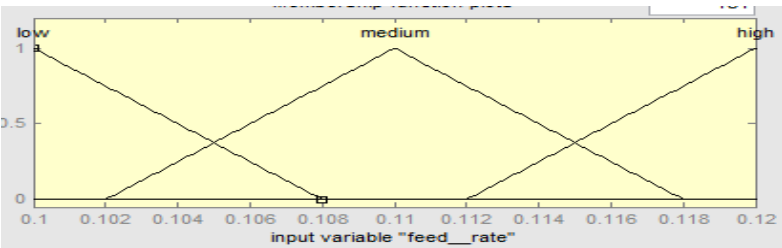

Fig. 4: Membership function vs. feed rate

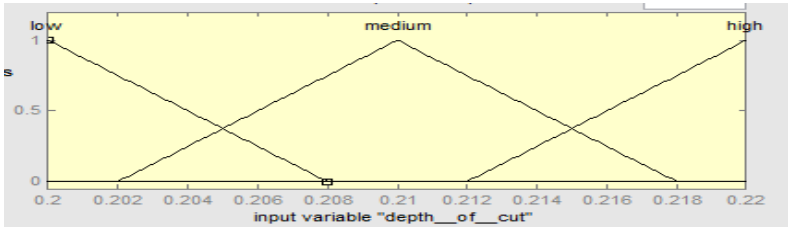

Fig. 5: Membership function vs. depth of cut

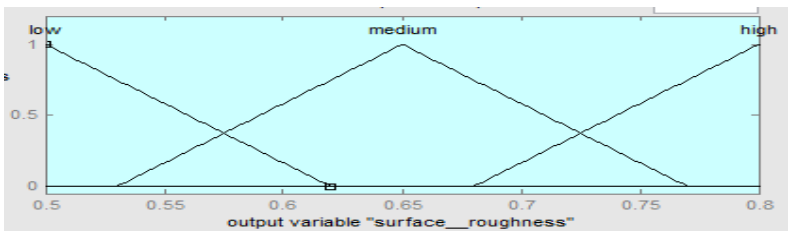

Fig. 6: Membership function vs. surface roughness

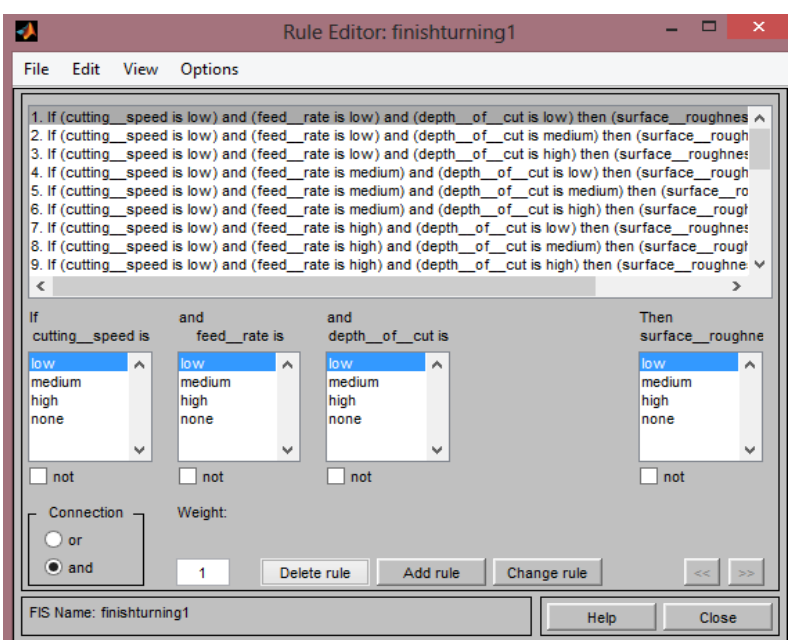

Fig 7: Rule base

All the 27 rules are defuzzied by fuzzy inference mechanism. The defuzzification is nothing but an aggregation method, to obtain a result. Centroid method is applied here for defuzzification.

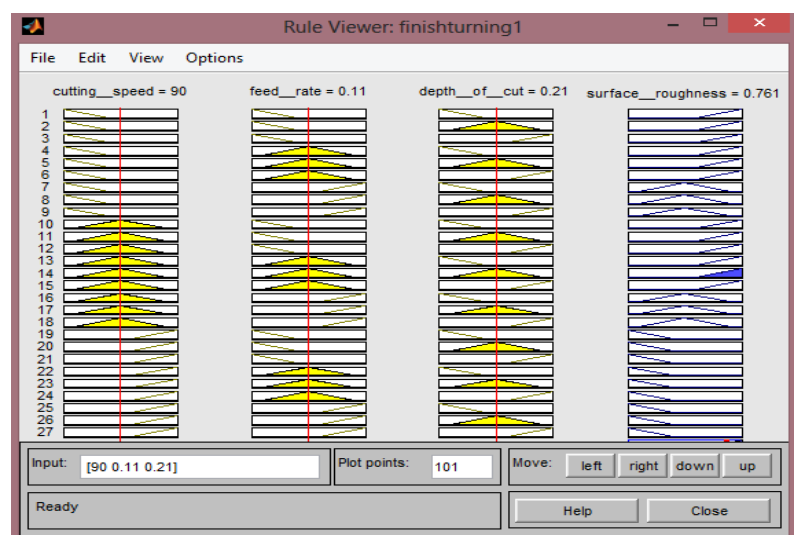

Fig 8: Defuzzification by fuzzy inference mechanism (rule viewer) 


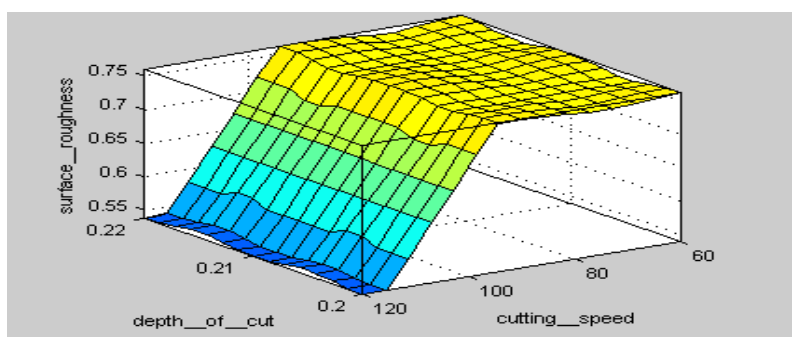

Fig 9(a): Surface view of rule viewer

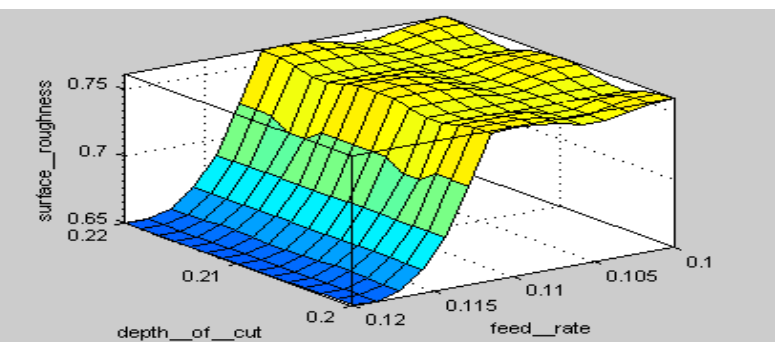

Fig 9(b): Surface view of rule viewer

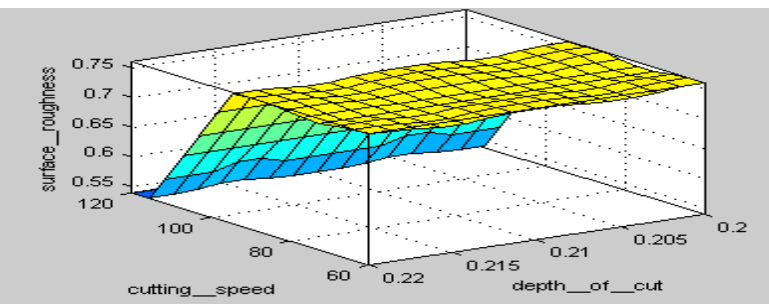

Fig 9(c): Surface view of rule viewer

\section{RESULT}

The Summarized Results by FIS are given below in table (3) and optimum result and surface view of optimum result shown in fig ( $10 \& 11)$ respectively.

Table 3. Result

\begin{tabular}{|c|c|c|c|c|}
\hline & \multicolumn{3}{|c|}{ Input parameters } & \multirow[t]{2}{*}{ Output variables } \\
\hline & $\mathrm{L}$ & $\mathrm{M}$ & $\mathrm{H}$ & \\
\hline 1 & $\mathrm{~L}$ & $\mathrm{~L}$ & $\mathrm{~L}$ & 0.761 \\
\hline 2 & $\mathrm{~L}$ & $\mathrm{~L}$ & $\bar{M}$ & 0.755 \\
\hline 3 & $\mathrm{~L}$ & $\mathrm{~L}$ & $\mathrm{H}$ & 0.751 \\
\hline 4 & $\mathrm{~L}$ & $\mathrm{M}$ & $\mathrm{L}$ & 0.752 \\
\hline 5 & $\mathrm{~L}$ & $\bar{M}$ & $\bar{M}$ & 0.750 \\
\hline 6 & $\mathrm{~L}$ & $\mathrm{M}$ & $\mathrm{H}$ & 0.743 \\
\hline 7 & $\mathrm{~L}$ & $\mathrm{H}$ & $\mathrm{L}$ & 0.679 \\
\hline 8 & $\mathrm{~L}$ & $\mathrm{H}$ & $\bar{M}$ & 0.656 \\
\hline 9 & $\mathrm{~L}$ & $\mathrm{H}$ & $\mathrm{H}$ & 0.650 \\
\hline 10 & $\mathrm{M}$ & $\mathrm{L}$ & $\mathrm{L}$ & 0.755 \\
\hline 11 & $\mathrm{M}$ & $\mathrm{L}$ & M & 0.741 \\
\hline 12 & M & $\mathrm{L}$ & $\mathrm{H}$ & 0.714 \\
\hline
\end{tabular}

\begin{tabular}{|c|c|c|c|c|}
\hline 13 & M & M & L & 0.708 \\
\hline 14 & M & M & M & 0.677 \\
\hline 15 & M & M & H & 0.655 \\
\hline 16 & M & H & L & 0.647 \\
\hline 17 & M & H & M & 0.634 \\
\hline 18 & M & H & H & 0.630 \\
\hline 19 & H & L & L & 0.627 \\
\hline 20 & H & L & M & 0.619 \\
\hline 21 & H & L & H & 0.604 \\
\hline 22 & H & M & L & 0.580 \\
\hline 23 & H & M & M & 0.567 \\
\hline 24 & H & M & H & 0.540 \\
\hline 25 & H & H & L & 0.541 \\
\hline 26 & H & H & M & 0.540 \\
\hline 27 & H & H & H & 0.539 \\
\hline
\end{tabular}

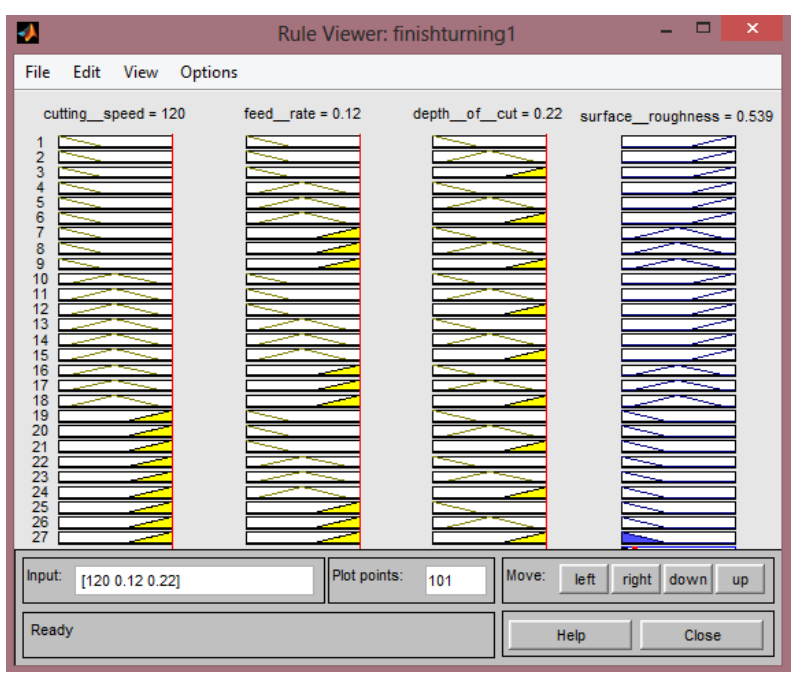

Fig 10: Optimum result obtained at $V=120 \mathrm{~m} / \mathrm{min}, f_{r}=$ $0.12 \mathrm{~mm} / \mathrm{rev}, \mathrm{DOC}=0.22 \mathrm{~mm}$

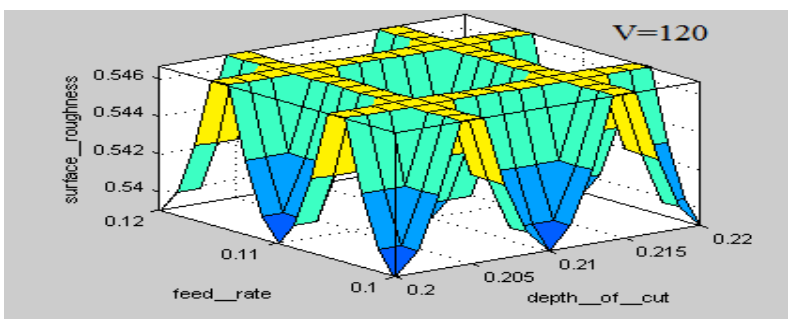

Figure 11: Surface view of optimum result

\section{CONCLUSIONS}

The proposed model of surface finish of hard-faced components has been designed using FL approach. The proposed model can be used in order to enhance the 
productivity and thus to reduce production cost. In the given model optimum value of surface roughness is obtained under: $\mathrm{V}=120 \mathrm{~m} / \mathrm{min}, \mathrm{FR}=0.11 \mathrm{~mm} / \mathrm{rev}$, and $\mathrm{DOC}=0.21 \mathrm{~mm}$. in the future work other parameters such as tool characteristics, working environment etc. can also be taken into consideration for the purpose. Similarly, MRR can also be considered as response parameter along with the surface roughness. In the future work, it is planned to validate the model made in this paper with some other soft computing techniques such as artificial neural networks, adaptive neural fuzzy inference system.

\section{ACKNOWLEDGMENTS}

I express my gratitude and sincere thanks to all the faculty members of production engineering department, BIT Sindri, Dhanbad, INDIA and at last but not the least I am very thanking full to my parents, siblings and friends for their full support during this paper work.

\section{REFERENCES}

[1] Black, J.T., Kohser, Ronald A., 2015, DeGarmo's Materials and Processes in Manufacturing, pp. 873.

[2] Gourd L.M., 1998. Principles of welding technology. Viva Books, New Delhi.

[3] Grinberg N. A. , Dzikovich N. N. , Nikolovenko M. P. , Khimicheskaya, Smrukmurnaya Niodnorodnosch, Svarochnoye Proizvodsmva, Svarochnoye Proizvodsmva, 1974, No. 4 pp. 7-9 (In Russian).

[4] E. Daniel Kirby, "Optimizing the Turning Process Toward an Idel Surface Roughness Target”, Journal of Industrial Technology, pp. 1-11, 2010.

[5] Kirchgaßner, M., Badisch, E., Franek, F. 2008, Behaviour of iron-based hard facing alloys under abrasion \& impact. Wear, Volume 265(5-6), pp. 772777.

[6] MATLAB 7.11.0 (R2010b).

[7] Pawade, R.S., "Multi-Objective Optimization of Surface Roughness and Cutting Forces in High-Speed Turning of Inconel 718 Using Taguchi Grey Relational Analysis (TGRA)", International Journal of Advance Manufacturing Technology, pp. 47-62, 2011

[8] Pradeep, G. R. C., Ramesh, A., Durga Prasad B., 2010. A Review Paper on Hard-facing Processes and Materials. International Journal of Engineering Science and Technology, Vol. 2(11), pp. 6507-6510.

[9] Pradeep, G.R.C., Ramesh, A. \& Durga Prasad B., 2013 Comparative Study of Hard-facing of AISI 1020 Steel by Three Different Welding Processes. Global Journal of Researches in Engineering Mechanical and Mechanics Engineering, volume 13 issue 4 version 1.0, pp. 11-16.

[10] Provolka Poroshkovaya Naplavochanya, Tekhnicheskiya Usloviya, M, 1984, Gost 26101- 84, pp. 14 (In Russian).

[11] Richard L.L., 1990, Welding and Welding Technology. Tata McGraw-Hill, New Delhi.

[12] Thamizhmanii, S., Saparudin, S. and Hasan, S., 2007 Analyses of Surface Roughness by Turning Process Using Taguchi Method. Journal of Achievements in Materials and Manufacturing Engineering, 20, pp. 503506.

[13] Zadeh, L. A., 1965. Fuzzy Sets. Information \& Control, Vol. 8, pp. 338 - 353. 